\title{
Molecular systematics of the subfamily Limenitidinae (Lepidoptera: Nymphalidae)
}

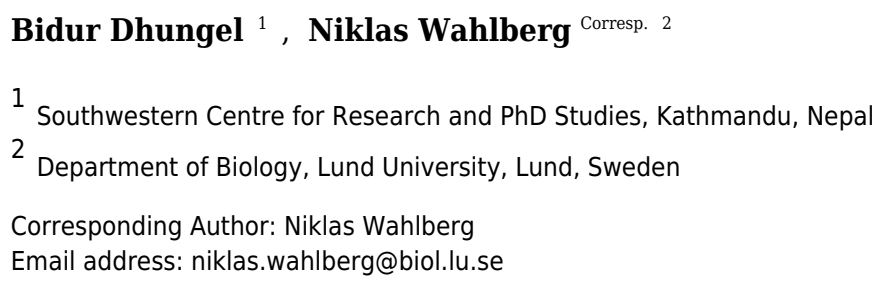

We studied the systematics of the subfamily Limenitidinae (Lepidoptera: Nymphalidae) using molecular methods to reconstruct a robust phylogenetic hypothesis. The molecular data matrix comprised 205 Limenitidinae species, four outgroups, and 11327 aligned nucleotide sites using up to 18 genes per species of which seven genes (CycY, Exp1, Nex9, Polll, ProSup, PSb and UDPG6DH) have not previously been used in phylogenetic studies. We recovered the monophyly of the subfamily Limenitidinae and seven higher clades corresponding to four traditional tribes Parthenini, Adoliadini, Neptini, Limenitidini as well as three additional independent lineages. One contains the genera Harma+Cymothoe and likely a third, Bhagadatta, and the other two independent lineages lead to Pseudoneptis and to Pseudacraea. These independent lineages are circumscribed as new tribes. Parthenini was recovered as sister to rest of Limenitidinae, but the relationships of the remaining six lineages were ambiguous. A number of genera were found to be nonmonophyletic, with Pantoporia, Euthalia, Athyma, and Parasarpa being polyphyletic, whereas Limenitis, Neptis, Bebearia, Euryphura, and Adelpha were paraphyletic. 
1 Molecular systematics of the subfamily Limenitidinae (Lepidoptera: Nymphalidae)

2

3 Bidur Dhungel ${ }^{1,2} \&$ Niklas Wahlberg ${ }^{1,3}$

$4{ }^{1}$ Department of Biology, University of Turku, Turku, Finland

$5 \quad{ }^{2}$ Southwestern Centre for Research and PhD Studies, Kathmandu, Nepal

$6{ }^{3}$ Department of Biology, Lund University, Lund, Sweden

7

8 Corresponding author: Niklas Wahlberg, niklas.wahlberg@biol.lu.se 


\section{Abstract}

We studied the systematics of the subfamily Limenitidinae (Lepidoptera: Nymphalidae) using molecular methods to reconstruct a robust phylogenetic hypothesis. The molecular data matrix comprised 205 Limenitidinae species, four outgroups, and 11327 aligned nucleotide sites using up to 18 genes per species of which seven genes (CycY, Exp1, Nex9, PolII, ProSup, PSb and UDPG6DH) have not previously been used in phylogenetic studies. We recovered the monophyly of the subfamily Limenitidinae and seven higher clades corresponding to four traditional tribes Parthenini, Adoliadini, Neptini, Limenitidini as well as three additional independent lineages. One contains the genera Harma+Cymothoe and likely a third, Bhagadatta, and the other two independent lineages lead to Pseudoneptis and to Pseudacraea. These independent lineages are circumscribed as new tribes. Parthenini was recovered as sister to rest of Limenitidinae, but the relationships of the remaining six lineages were ambiguous. A number of genera were found to be non-monophyletic, with Pantoporia, Euthalia, Athyma, and Parasarpa being polyphyletic, whereas Limenitis, Neptis, Bebearia, Euryphura, and Adelpha were paraphyletic.

This published work has been registered in ZooBank (urn:Isid:zoobank.org:pub:A422503C-2E624001-8397-B8C9085CB23C)

\section{Introduction}

The butterfly family Nymphalidae has been the subject of intensive research in many fields of biology over the decades. However, the higher classification of the family is still being worked on, with the delineation of subfamilies being established fairly recently (Wahlberg et al., 2009). It is now clear that there are 12 subfamilies that are well supported by both molecular (Brower, 2000; Wahlberg, Weingartner \& Nylin, 2003; Wahlberg et al., 2009) and morphological data (Freitas \& Brown, 2004). These subfamilies have been accepted by most of the community working on Nymphalidae. The relationships of major lineages within subfamilies are now under scrutiny, with work at the level of subfamily already done on Apaturinae (Ohshima et al., 2010), Libytheinae (Kawahara, 2009), Nymphalinae (Wahlberg, Brower \& Nylin, 2005) and Satyrinae (Peña et al., 2006), as well as a multitude of studies looking at relationships at lower levels 
40

41

42

43

44

within subfamilies. Here we turn our attention to Limenitidinae, a subfamily with a complex taxonomic history.

The rank and position of Limenitidinae has always been unstable and long debated among researchers. Popularly known as a "trash can" subfamily, Limenitidinae has included groups of species that could not be placed in any recognized subfamilies and were thus retained in the subfamily just for convenience (Harvey, 1991; Neild, 1996; Brower, 2000). Historically, Limenitidinae were placed as a tribe in the subfamily Nymphalinae (Smart, 1975). Later, Harvey (Harvey, 1991) placed Limenitidinae as the tribe Limenitidini in the subfamily Limenitidinae (sensu Harvey) but together with three unrelated tribes Coloburini (sensu Harvey), Biblidini (sensu Harvey), Cyrestidini (sensu Harvey), and two genera Pseudergolis and Stibochiona (now in the subfamily Pseudergolinae). Limenitidinae (sensu Harvey) is equivalent to Müller's (Müller, 1886) group III together with Cyrestidini (Harvey, 1991). Molecular work has finally unambiguously delineated the subfamily Limenitidinae (Brower, 2000; Wahlberg, Weingartner \& Nylin, 2003; Wahlberg et al., 2009). Based on molecular data, the subfamily Limenitidinae is equivalent to the tribe Limenitidini of Harvey, it is sister to the subfamily Heliconiinae and does not include the taxa Cyrestidinae, Biblidinae, and Pseudergolinae (Brower, 2000; Wahlberg, Weingartner \& Nylin, 2003; Freitas \& Brown, 2004; Wahlberg et al., 2009).

As it is currently delineated, the subfamily Limenitidinae (Lepidoptera: Nymphalidae) comprises a little over 800 species placed in 46 genera and four tribes: Parthenini, Adoliadini (=Euthaliini), Limenitidini, and Neptini (Wahlberg, 2007). Limenitidinae are distributed worldwide and occur in all major biogeographical regions: Nearctic, Neotropics, Palaearctic, Afrotropics, Oriental, and Australasia (Chermock, 1950; Chou, 1998; Willmott, 2003). The species of the tribe Parthenini are limited to the Oriental and Australasian regions while the species of the tribes Neptini and Adoliadini are distributed throughout the Old World tropics. The species of the tribe Limenitidini are distributed mainly in the Palaearctic and the New World. It should be noted that some studies (e.g. Mullen et al., 2011) have included Lelecella as a limenitidine, although this genus is in fact in the subfamily Apaturinae.

Initial studies on Limenitidinae were mostly limited to the description of new species and genera. Schatz (1892) studied and classified the Limenitidinae of the world in three tribes ("Neptis-Gruppe", "Limenitis-Gruppe", and "Euthalia-Gruppe") based on venation and palpal 
structures. Later, Reuter (1896) classified Limenitidinae into two tribes: Limenitidi and Neptidi based on studies of the palpi. The tribe Limenitidi (including the Euthalid complex) was further subdivided in two subtribes Limenitini and Parthenini. Moore (1890-1907) surveyed the limenitidines of south eastern Asia introducing many new generic names and grouped them into two tribes Euthaliina and Limenitina (Neptis included) based on venation and maculation. Moore's Euthaliina is a synonym of Adoliadina described earlier by Doubleday based on the genus Adolias (itself a synonym of Euthalia). Moore's name Euthaliina has been in common use, as the following narrative shows. Aurivillius (Aurivillius, 1898) also surveyed and grouped the African Limenitidinae under two tribes Neptididi and Nymphalidi. According to Chermock (1950) most of species of Limenitidinae (except Neptis) can be distinguished from all other nymphalids by the first anal vein of the forewing that is preserved as a short spur at the base of the cubitus. Chermock (1950) considered Limenitidinae of the world to belong to one tribe Limenitini based on venation, male genitalia, life histories, maculation, palpal characters, and distribution. Based on egg morphology and following Eliot (1978), Harvey (1991) divided the tribe Limenitidini into four subtribes: Limenitiditi, Neptiti, Partheniti, and Euthaliiti. However, Chou has divided Asian Limenitidinae into 5 tribes Euthaliini, Parthenini, Neptini, Limenitini, and Chalingini based on morphological characters (Chou, 1998; Zhang et al., 2011). Willmott (2003) suspected that Chalingini does not belong in Limenitidinae based on their unique morphology. In addition to ambiguous higher classification in Limenitidinae, many genera are vaguely defined or supported by few characters (Willmott, 2003).

The systematic relationships within Limenitidinae among its major lineages are still unclear. There have been some genus level phylogenetic studies (Willmott, 2003; Mullen, 2006; Mullen et al., 2011; van Velzen et al., 2013; Ebel et al., 2015) and some phylogenetic studies included a few genera of the subfamily Limenitidinae (Zhang et al., 2008; Zhang et al., 2011; Wu et al., 2014). However, a comprehensive phylogenetic study of the entire subfamily at the genus and tribe level is still lacking, thus hindering evolutionary studies of the subfamily. Furthermore, a solid phylogenetic hypothesis of Limenitidinae is required to study the evolutionary processes that drive rates of diversification in the subfamily.

Our aims are to study systematics of the subfamily Limenitidinae using up to 18 gene regions per species of 205 taxa belonging to recognized genera and tribes of Limenitidinae spanning all 
100 major biogeographical areas. We also introduce seven new gene regions (CycY, Exp1, Nex9,

101 PolII, ProSup, PSb and UDPG6DH) used in this study which have never been previously used 102 for phylogenetic studies.

103 Material and methods

104 Taxon Sampling

105 A total of 205 samples representing 39 genera and all four traditional tribes (Table S1): 106 Parthenini, Neptini, Adoliadini and Limenitidini of the subfamily Limenitidinae were collected 107 either by the authors during field visits or by various collaborators. Samples were acquired from 108 all major biogeographical areas. Unfortunately, we could not obtain sequence data from three 109 potentially important genera (Neurosigma, Euryphaedra, and Kumothales). Four exemplar taxa from the sister subfamily Heliconiinae: Argynnis, Heliconius, Actinote, and Cethosia were selected as outgroups to root the topology of the subfamily Limenitidinae.

112 Genomic DNA was mainly extracted from one or two legs, and in a few cases thoracic tissue, 113 of dried mounted vouchers or ethanol-preserved specimens of butterflies. Genomic DNA was extracted using the Qiagen DNEasy extraction kit, following the protocol from the manufacturer.

115 For each species, we amplified and sequenced 1 gene from mitochondrial genome (cytochrome 116 oxidase subunit I, COI) and 17 genes from nuclear genomes, of which carbamoylphosphate 117 synthetase (CAD), Ribosomal Protein S5 (RpS5), Ribosomal Protein S2 (Rps2), wingless (wgl), 118 cytosolic malate dehydrogenase (MDH), glyceraldehydes-3-phosphate dehydrogenase 119 (GAPDH), Elongation factor 1 alpha (EF-1a), Arginine Kinase (ArgKin), Isocitrate 120 dehydrogenase (IDH) and dopa-decarboxylase (DDC) were amplified using primers and 121 protocols from Wahlberg and Wheat (2008). For the new gene regions Cyclin $Y(\mathrm{CycY})$, 122 exportin-1-like (Exp1), sorting nexin-9-like (Nex9), DNA-directed RNA polymerase II 123 polypeptide (PolII), suppressor of profiling 2 (ProSup), proteasome beta subunit (PSb), UDP 124 glucose6 dehydrogenase (UDPG6DH) as well as a different section of ArgKin we used primer 125 pairs and protocols described by Wahlberg et al. (2016). For a number of species, sequences 126 were downloaded from GenBank (accession numbers in Table S1).

127 Successful amplicons were cleaned with A'SAP (ArticZymes) and Sanger sequenced 128 (Macrogen Services, Amsterdam). Previously published DNA sequences (Wahlberg et al., 2009; 
129 Mullen et al., 2011; van Velzen et al., 2013; Wu et al., 2014) were also included in the current 130 study. Nucleotide sequence alignment was manually done using the program Bioedit (Hall, 131 1999). Sequences were managed and datasets were constructed using VoSeq v1.7.4 (Peña \& 132 Malm, 2012).

133

134

135

136

137

138

139

140

141

142

143

144

145

146

147

148

149

150

151

152

153

154

155 156

\section{Phylogenetic inference}

Phylogenetic analyses were done first separately for each gene (producing gene trees) and then for all the 18 genes combined. The combined dataset is given in Supplemental Data S1. We explored various partitioning schemes of our concatenated multi-gene dataset using PartitionerFinder v1.1.1 (Lanfear et al., 2012) and compared them based on the Bayesian Information Criterion (BIC). We first partitioned by gene and codon positions and ran PartitionFinder in order to find which subsets could be combined. In addition, we calculated the relative rates of evolution for each site in the alignment using TIGER (Cummins \& McInerney, 2011) and created partitions using the RatePartitions algorithm (Rota, Malm \& Wahlberg, 2017).

We tested a range of $d$ values (2.0 to 5.0, with increments of 0.5 ), which affects the number of partitions, and calculated their BIC values in PartitionFinder.

Phylogenetic inference analyses were carried out using both Maximum likelihood (ML) and Bayesian Inference (BI) methods. Maximum likelihood phylogenetic inference analyses were carried out in RAxML v8.2.4 (Stamatakis, 2014) on XSEDE on the CIPRES Science Gateway v3.3 (Miller, Pfeiffer \& Schwartz, 2010) using the best partition scheme suggested by the PartitionFinder/TIGER analysis based on BIC. For bootstrapping, we performed 1000 Maximum Likelihood (ML) pseudo-replicates analyses and bootstrapping was performed under auto Majority Rule Criterion (autoMRE). Similarly, BI was performed using Markov Chain Monte Carlo (MCMC) in MrBayes v3.2.6 (Ronquist et al., 2012) on XSEDE on the CIPRES Science Gateway v3.3 (Miller, Pfeiffer \& Schwartz, 2010). Two parallel runs of four chains (3 heated and 1 cold) were performed for 20 million generations, with sampling done at every $1000^{\text {th }}$ generation. The software Tracer v1.6 (Rambaut et al., 2014) was used to inspect the sample sizes of the parameters used in the BI and also check for the convergence or otherwise of the parallel MCMC runs. 
157 As there was a lot of missing data for many specimens (Table S1), we also analysed a subset of 158 taxa that had 10 or more gene regions sequenced. This set of 55 taxa (including all the 159 outgroups) was analysed with RAxML as described above, partitioned by gene.

160

161

162

163

164

165

166

167

168

169

170

171

172

173

174

175

176

177

178

179

180

181

182

183

\section{Taxonomic decisions}

The electronic version of this article in Portable Document Format (PDF) will represent a published work according to the International Commission on Zoological Nomenclature (ICZN), and hence the new names contained in the electronic version are effectively published under that Code from the electronic edition alone. This published work and the nomenclatural acts it contains have been registered in ZooBank, the online registration system for the ICZN. The ZooBank LSIDs (Life Science Identifiers) can be resolved and the associated information viewed through any standard web browser by appending the LSID to the prefix http://zoobank.org/. The LSID for this publication is: urn:Isid:zoobank.org:pub:A422503C-2E62-4001-8397-B8C9085CB23C. The online version of this work is archived and available from the following digital repositories: PeerJ, PubMed Central and CLOCKSS.

\section{Results}

\section{Molecular data}

Our final molecular data matrix consisted of 209 taxa representing 205 Limenitidinae species; four related taxa as outgroups; and 11327 aligned nucleotide sites with no indels. In this study, we used 18 genes of which seven genes (CycY, Exp1, Nex9, PolII, Prosup, PSb and UDPG6DH) have not been previously used in phylogenetic studies of Nymphalidae butterflies. Table 1 gives the basic statistics for variation in each gene region. The new gene regions show similar amounts of variation to the standard gene regions of Wahlberg and Wheat (2008).

The best partitioning scheme was evaluated based on BIC values as calculated by PartitionFinder (Lanfear et al., 2012). Partitioning strategies based on genes were decisively worse than those based on RatePartitions or partitioning by gene and codon position (Table 2). The best partitioning scheme was created by RatePartitions with $d=5.0$, which subdivided the data into 19 partitions. This partitioning scheme had a BIC value 543 units lower than the next best 
184 scheme based on partitioning by gene and codon position. We thus used the RatePartitions 5.0 185 scheme for further analyses.

186 Systematics

187 With four outgroups, the maximum Likelihood (ML) (Fig. 1) and Bayesian Inference (BI) (Fig. 188 S1) methods recovered the subfamily Limenitidinae as monophyletic with strong bootstrap 189 supports (BS 100) and high posterior probabilities (PP 1.0). Our analyses recovered seven major 190 lineages: a clade including species of the tribe Parthenini, a clade including Bhagadatta, Harma 191 and Cymothoe, a clade including Pseudacraea, a clade including species of the tribe Neptini, a 192 clade including species of tribe Adoliadini, a clade including Chalinga pratti and species of the 193 core tribe Limenitidini (Harvey, 1991) and finally an independent lineage leading to 194 Pseudoneptis bugandensis of the tribe Limenitidini. Most of these clades are strongly supported, 195 the exceptions are the position of Chalinga as sister to the core Limenitidini and the sister 196 position of Bhagadatta to Cymothoe and Harma. The relationships of six of the seven lineages 197 are not resolved despite increased gene region sampling, only the sister relationship of Parthenini 198 to the rest of Limenitidinae is strongly supported. Reducing the taxon sampling to only those 199 taxa with 10 or more gene regions sequenced did not change the fundamental results in any way 200 (Fig. S2).

201 The relationships within the Cymothoe clade are very similar to those reported in a previous 202 study of the genus (van Velzen et al., 2013), with the exception of the genus Bhagadatta which 203 appears to be sister to Cymothoe and Harma with low to moderate support (BS 57, PP 0.98).

204 The genus Pseudacraea formed an independent lineage that appears to be sister to Neptini with 205 no support in ML (BS 39) and moderate support in BI (PP 0.98). Relationships of species within 206 Pseudacraea were generally well supported and clear, with P. poggei and P. lucretis being the 207 sister group of the rest of the genus.

208 In Neptini, we found the genus Lebadea to be sister to the rest of the tribe, with the core 209 Pantoporia branching off next and Lasippa being sister to Neptis s.l. We recovered the genus 210 Pantoporia as polyphyletic and Neptis as paraphyletic. The species Pantoporia venilia from 211 Australia was found to be sister to a clade of African species of Neptis with low support values 212 (BS 65, PP 0.53), but certainly within a strongly supported (BS 100, PP 1.0) derived clade of 
213 Neptis. The species Phaedyma aspasia was also found within one of the well supported Asian

214 Neptis clades. Asian species of Neptis formed a grade while all sampled African species were

215 found in a strongly supported clade (BS 98, PP 1.0).

216 In Adoliadini, we found five well supported clades, the Asian Euthalia clade, and the African

217 Euptera, Hamanumida, Catuna and Bebearia clades. Relationships of these five lineages were

218 not well supported, with the African clades forming a monophyletic group in the ML analyses

219 (BS 65), but not in the BI analyses, where the Euptera clade was the sister to the rest of 220 Adoliadini (PP 1.0). The Palaearctic species Abrota ganga was sister to the Hamanumida clade 221 with very high support values (BS 99, PP 1.0) rather than clustering with other Asian Adoliadini. 222 We recovered the genus Euthalia as polyphyletic, with Euthalia adonia being the sister to 223 Dophla evelina with strong support while Euthalia monina was sister to species of the genera 224 Tanaecia with strong support values. Bebearia was found to be paraphyletic with regard to 225 Euphaedra with low bootstrap (BS 58) but high posterior probability (PP 0.99). The species 226 Crenidomimas concordia was found to be nested within the species Euryphura chalcis with all 227 three specimens being genetically very similar.

228 We found Chalinga pratti to be sister to the core Limenitidini with low or no support (BS 60, PP 229 0.56), but this position was consistent and stable in all analyses. Within the core Limenitidini 230 there are five well supported lineages, with Tacola sister to the rest, Moduza branching off next, 231 then the Athyma clade, and finally Parasarpa zayla as sister to the Limenitis clade. The genus 232 Tarattia was found to be within Moduza. The Athyma clade comprises the paraphyletic Athyma 233 with the genera Sumalia, Pandita and Lamasia deeply within the genus. Also the Limenitis clade 234 shows nonmonophyletic genera: Parasarpa, Limenitis and Adelpha are intermixed and the clade 235 contains the genera Auzakia and Patsuia. Relationships differ somewhat between the ML and BI 236 analyses in this part of the tree, especially where branch lengths are very short or nonexistent.

\section{Discussion}

238 Systematic implications

239 Here, we studied molecular systematics of the recently defined (Wahlberg et al., 2009) subfamily 240 Limenitidinae. Previous studies (Brower, 2000; Wahlberg, Weingartner \& Nylin, 2003; Freitas 241 \& Brown, 2004) clearly showed that the traditional view of the subfamily Limenitidinae (e.g. 
242 Harvey, 1991) was not monophyletic. Wahlberg et al. (2009) defined the subfamily but did not

243 discuss the internal relationships. We recovered seven independent lineages corresponding to 244 four tribes Parthenini, Neptini, Adoliadini, Limenitidini; as well as three independent lineages 245 without formal tribal names: the Cymothoe clade, Pseudoneptis and Pseudacraea (Fig. 1). For 246 consistency, when discussing previous publications, we will align taxon concepts with ours, e.g. 247 our concept of the subfamily Limenitidinae has often been referred to as the tribe Limenitidini, 248 and our tribes as subtribes.

249 Many of the relationships we found were surprising, but some were anticipated by Willmott 250 (2003) based on careful morphological comparisons. For instance he noted similarities in male 251 genitalia between Lebadea and Neptis, suggested that Bhagadatta might be related to Cymothoe, 252 that Tacola is sister to the rest of Limenitidini, maintained that Parthenos is the only genus to be 253 included in Parthenini, and proposed that Cymothoe be placed in a tribe of its own. Willmott 254 (2003) also suggested that Neptini was not a separate entity from Limenitidini, as did Amiet 255 (2000), whereas based on our analyses it is clearly a separate entity that is not even sister to 256 Limenitidini.

257 With the exception of the position of Parthenini as sister to the rest of Limenitidinae, the 258 relationships of the major lineages within the subfamily were poorly supported despite up to 18 259 gene regions being sequenced for specimens within each lineage. The branches subtending these lineages are characterised by very short lengths, suggesting a period of rapid divergences. Such patterns are repeated throughout the evolutionary history of Limenitidinae, notably within Cymothoe (van Velzen et al., 2013), Euriphene, Euphaedra and the base of the Limenitis clade.

\section{Parthenini}

264

265

266

As anticipated by Willmott (2003), our data recovered only species of Parthenos in this tribe and its position as sister to the rest of Limenitidinae was recovered with strong support in all phylogenetic analyses. Similar results were also found by (Zhang et al., 2008; Zhang et al., 2011; Wu et al., 2014). Parthenos is limited to the Indo-Australian region.

\section{Cymothoini Dhungel \& Wahlberg trib. nov.}

LSID urn:Isid:zoobank.org:act:C26A6D77-EDE1-43DB-919F-254E47B82CA3 
270 Based on our results, the genera Cymothoe, Harma and likely Bhagadatta form an independent

271 lineage that warrant tribal status. Harvey (1991) classified the two African genera Harma and 272 Cymothoe in the tribe Limenitidini. However, Amiet (Amiet, 2001) and Willmott (2003) 273 regarded Cymothoe (including Harma) as incertae sedis, as they share more morphological 274 features with Adoliadini than with Limenitidini. The genera Harma and Cymothoe were 275 recovered as sister to each other with strong support values. The Harma+Cymothoe sister clade 276 relationship was consistent with the previous study by van Velzen et al. (2013). Harma and 277 Cymothoe are here placed in a new tribe Cymothoini Dhungel \& Wahlberg trib. nov. The tribe 278 forms a strongly supported clade comprising species placed in Cymothoe and Harma with DNA 279 sequence data from the following gene regions (exemplar sequences from Cymothoe caenis) 280 ArgKin (GQ864537), CAD (GQ864636), COI (GQ864754), CycY (MG741765), DDC 281 (MG741734), EF1a (GQ864848), GAPDH (GQ864952), IDH (GQ865083), MDH (GQ865196), 282 Nex9 (MG741407), PolII (MG741353), ProSup (MG741316), PSb (MG741271), RpS2 283 (GQ865312), RpS5 (GQ865420), UDPG6DH (MG741133) and wingless (GQ864442).

284 Surprisingly, we recovered species Bhagadatta austenia as a sister to genera Harma+Cymothoe 285 but with a weak support values (BS 57, PP 0.98). Bhagadatta austenia has been classified in the 286 tribe Limenitidini by Harvey (1991) and Wu et al. (2014) but incertae sedis by Willmott (2003), 287 who noted similarities in genitalia with Cymothoe. We retain Bhagadatta as incertae sedis in 288 Limenitidinae, but suggest that it might be placed in the new tribe Cymothoini once further 289 information is available. Interestingly, Bhagadatta is restricted to Asia whereas Harma and 290 Cymothoe are African genera. Only COI sequences were available for Bhagadatta from the study 291 of Wu et al. (2014), thus it is imperative that nuclear genes are sequenced from this taxon to test 292 its position.

293 Neptini

294 Neptini including Lebadea was recovered as monophyletic with moderate support (BS 75, PP 295 0.98). The monotypic genus Lebadea was classified as a member of tribe Parthenini by Harvey, 296 but Willmott (2003) removed it to Limenitidini and suggested similarities to Neptis in male 297 genitalia. Wahlberg et al. (2009) found the genus to be sister to Neptini, with no comment, a 298 position that we corroborate here with more data. The core Neptini, including the genera Neptis, 
299 Pantoporia, Lasippa and Phaedyma, form a strongly supported clade, with Pantoporia being 300 sister to Lasippa and Neptis, and Phaedyma aspasia being within Neptis. Phaedyma aspasia was 301 originally described in Neptis by Leech but has been placed in Phaedyma by various authors, e.g. 302 Chou (1998). Unfortunately we were not able to sample the type species of the genus Phaedyma 303 (P. heliodora, synonym of $P$. amphion), thus we are unable to say whether the genus should be 304 synonymized with Neptis. We propose a revised combination, Neptis aspasia comb. rev. 305 Similarly, Pantoporia venilia does not belong in the genus Pantoporia, but is clearly within 306 Neptis, leading to another revised combination Neptis venilia comb. rev.

307 The species of Neptis are distributed throughout Asia, Africa, Australia, and Europe, with the 308 center of diversity being SE Asia. Our results suggest that the African species form a monophyletic group, with four Asian clades forming a paraphyletic grade with regard to the African clade.

Pseudacraeini Dhungel \& Wahlberg trib. nov.

LSID urn:Isid:zoobank.org:act:E9569B8F-4D9D-4BCC-A18F-431557043079

313

314

315

316

317

318

319

320

321

322

323

324

325

326

Our results recovered the genus Pseudacraea as a monophyletic group with strong support values, and suggest that Pseudacraea might be sister to Neptini, although with no support in ML. Pseudacraea has been classified as Limenitidini (Harvey, 1991; Willmott, 2003). Amiet (2000) and Willmott (2003) suggest that Pseudacraea share synapomorphies with Limenitidini and Neptini, and indeed our ML topology suggests that these three lineages form a monophyletic group, however with no support at all. It appears that Pseudacraea is an independent lineage much like Pseudoneptis and the Cymothoe clade, and is thus placed in a tribe of its own: Pseudacraeini Dhungel \& Wahlberg trib. nov. The tribe comprises species in the genus Pseudacraea and can be characterized by the DNA sequence data from the following gene regions (example from Pseudacraea poggei) ArgKin (MG741852), CAD (GQ864704), COI (GQ864802), CycY (MG741798), EF1a (GQ864896), Exp1 (MG741609), GAPDH (GQ865024), IDH (GQ865143), MDH (GQ865258), Nex9 (MG741441), PolII (MG741387), ProSup (MG741336), PSb (MG741302), RpS2 (GQ865362), RpS5 (GQ865489), UDPG6DH (MG741157) and wingless (GQ864490). 
327

328

329

330

331

332

333

334

335

336

337

338

339

340

341

342

343

344

345

346

347

348

349

350

351

352

353

354

355

Adoliadini

The monophyly of Adoliadini is strongly supported (BS 91, PP 1.0). This tribe contains species from genera that are distributed in both Asia and Africa. Based on biogeography, Adoliadini could be divided into two subtribes: Adoliadina (Euthalia clade) for the Asian and Bebearina (Hamanumida, Bebearia and Catuna clades) for African species. This division does not take into account the African Euptera clade, containing the genera Euptera and Pseudathyma, which does not have a stable position in our analyses, being either sister to all Adoliadini (BI, PP 1.0) or sister to the other African clades (ML, BS 65). This suggests that using the concept of subtribe is not particularly useful in this case. Surprisingly, the Asian genus Abrota was sister to the African Hamanumida clade with strong support values (BS 99, PP 1.0) rather than clustering with other Asian Adoliadini.

The genus Euthalia was recovered as paraphyletic with Euthalia monina being sister to Tanaecia and Euthalia adonia being sister to Dophla with strong support values. This pattern is intriguing and calls for a much more detailed study of the species rich genus Euthalia. Another intriguing pattern is the genetic similarity of Crenidomimas concordia with Euryphura chalcis. These two taxa are very different based on wing patterns, with Crenidomimas perhaps mimicking the genus Sevenia (Nymphalidae: Biblidinae), but clearly they are very closely related to each other and should be the focus of a more detailed study. The genus Bebearia was also found to be paraphyletic with regard to Euphaedra, although with only moderate support in ML analyses. This clade also requires further study in order to establish whether a new genus needs to be described.

\section{Limenitidini}

The position of Chalinga pratti (also known as Seokia pratti) as sister to the core Limenitidini was stable across all analyses, but never had high support. As noted in the Introduction, Chou (1998) placed Chalinga in its own tribe Chalingini and Willmott (2003) suspected that Chalinga (including Seokia) perhaps did not belong to Limenitidinae. Our results show that it does indeed belong to the subfamily, and is likely to be the sister group to the core Limenitidini. For the time being we prefer to keep Chalinga in the tribe Limenitidini until there is further evidence that it should be considered a separate lineage worthy of tribal status. 
356 The core Limenitidini comprises five distinct lineages, of which three show para- and polyphyly

357 of constituent genera. These are the Moduza, Athyma and Limenitis clades. In addition, the genus

358 Tacola and the species Parasarpa zayla form independent lineages. Two species endemic to

359 Sulawesi have been removed from Moduza and placed in the genus Tarattia (Hanafusa, 1989;

360 Tsukada, 1991), of which we sampled T. lysania. We found T. lysania to be sister to Moduza

361 lymire, also endemic to Sulawesi, but retained in the genus Moduza (Vane-Wright \& de Jong,

362 2003). We suggest that until further evidence shows that the Sulawesian clade is clearly sister to

363 Moduza and not within it, Tarattia should be considered a synonym of Moduza. The genus

364 Athyma has three relatively small genera within it: Pandita, Sumalia, and Lamasia. Lamasia

365 lyncides was separated from Moduza by Tsukada (1991), but appears to actually be a species of

366 Athyma. As the three genera are well within Athyma, they should be synonymized with it.

367 The phylogenetic relationships of genera within the Limenitis clade are complex and unresolved.

368 The type species of the genus Parasarpa (P. zayla) is an independent lineage sister to the

369 Limenitis clade with good support, but other members of the genus are found within the clade in

370 an unresolved position. Adelpha is found in two well supported clades that may or may not be

371 sister to each other, a result also found by Mullen et al. (2011). The monotypic Patsuia appears

372 to be sister to the type species of Limenitis (L. populi) and thus the former can be synonymized

373 with the latter genus. The position of the monotypic Auzakia varies depending on the method of

374 analysis, with ML placing it as sister to the rest of the Limenitis clade, while Bayesian inference

375 places it within Limenitis. On the whole, the genus Limenitis presents a challenge for

376 classification and clearly more data are necessary to resolve the relationships

377 Pseudoneptini Dhungel \& Wahlberg trib. nov.

The genus Pseudoneptis was classified in the tribe Limenitidini by Harvey (1991) but incertae sedis by Willmott (2003). In this study, Pseudoneptis is recovered as sister either to the

381 Cymothoe clade or to Limenitidini depending on method of analysis, i.e. it is highly unstable.

382 Given that we have sequenced 14 gene regions from our specimen, the instability is more likely 383 to be due to a rapid divergence scenario than a lack of data. This suggests that Pseudoneptis 384 should be placed in a tribe of its own, especially since the single species in the genus has a suite 
385 of apomorphies (Amiet, 2002). We thus erect a monotypic tribe Pseudoneptini Dhungel \& 386 Wahlberg trib. nov. for the species Pseudoneptis bugandensis. Apomorphies for the tribe are 387 described in Amiet (2002) and the lineage is also diagnosed by the the unique combination of 388 DNA sequence data from the following gene regions ArgKin (MG741830), CAD (GQ864705), 389 COI (GQ864803), CycY (MG741777), EF1a (GQ864897), GAPDH (GQ865025), IDH 390 (GQ865144), MDH (GQ865259), Nex9 (MG741419), PolII (MG741365), PSb (MG741283), 391 RpS2 (GQ865363), UDPG6DH (MG741142) and wingless (GQ864491).

392 Conclusion

393 This study presents the most comprehensive phylogenetic analysis to date for the "trash-can" 394 subfamily Limenitidinae. Based on fragments of up to 18 genes per species, 205 species and four 395 outgroups, our results recovered Limenitidinae as a monophyletic clade and which comprises 396 seven major lineages that deserve tribal status. Four tribes have been traditionally recognized: 397 Parthenini, Neptini, Adoliadini, and Limenitidini, while three lineages are placed in new tribes 398 here: Cymothoini, Pseudoneptini and Pseudacraeini. The new Cymothoini tribe includes two 399 African genera Cymothoe and Harma, and quite likely an Asian genus Baghadatta. The latter 400 two new tribes are monogeneric. At the genus level, we found several traditionally recognized 401 genera to be either poly- or paraphyletic, i.e. Neptis, Euryphura, Pantoporia, Athyma, 402 Parasarpa, Limenitis, and Adelpha. Further work increasing the taxon sampling is necessary to 403 test the monophyly of these genera and revise their limits.

404

405 406 407 408 409

410

411

412

Acknowledgments

We are grateful to the late Torben Larsen, Zdenek Fric, Freerk Molleman, Kwaku Aduse-Poku, Steve Collins and the African Butterfly Research Institute for providing specimens for this work. We thank Pavel Matos-Maravi, Jenni Mäkynen and Evelyn Sanchez for help in the lab. We thank Martin Weimers and an anonymous referee for comments on a previous version of the manuscript. 
413

414

415

416

417

418

419

420

421

422

423

424

425

426

427

428

429

430

431

432

433

434

435

436

437

438

439

440

441

442

443

444

445

446

447

448

449

450

451

452

453

454

455

456

457

458

Amiet J-L. 2000. Premiers é tats de Pseudacraea et Neptis du Cameroun: morphologie et éthologie comparé es, phylogénie (Lepidoptera, Nymphalidae). Bulletin de la Société Entomologique de France 105:131-174.

Amiet J-L. 2001. Les premiers états des Cymothoe: morphologie et intéret phylogénique (Lepidoptera, Nymphalidae). Bulletin de la Société Entomologique de France 106:349390.

Amiet J-L. 2002. A propos des premiers é tats de Pseudoneptis bugandensis Stoneham, 1935 (Lepidoptera, Nymphalidae). Bulletin de la Société Entomologique de France 107:231242.

Aurivillius C. 1898. Rhopalocera Aethiopica die Tagfalter des Aethiopischen Faunengebietes eine systematisch-geographische studie. Kungliga Svenska Vetenskapsakademiens Handlingar 31:1-561.

Brower AVZ. 2000. Phylogenetic relationships among the Nymphalidae (Lepidoptera), inferred from partial sequences of the wingless gene. Proceedings of the Royal Society of London B Biological Sciences 267:1201-1211. 10.1098/rspb.2000.1129

Chermock RL. 1950. A generic revision of the Limenitini of the world. American Midland Naturalist 43:513-569.

Chou I. 1998. Classification and Identification of Chinese Butterflies. Henan, China: Henan Scientific and Technological Publishing House.

Cummins CA, and McInerney JO. 2011. A method for inferring the rate of evolution of homologous characters that can potentially improve phylogenetic inference, resolve deep divergence and correct systematic biases. Systematic Biology 60:833-844. 10.1093/sysbio/syr064

Ebel ER, DaCosta JM, Sorenson MD, Hill RI, Briscoe AD, Willmott KR, and Mullen SP. 2015. Rapid diversification associated with ecological specialization in Neotropical Adelpha butterflies. Molecular Ecology 24:2392-2405. 10.1111/mec.13168

Eliot JN. 1978. The Butterflies of the Malay Peninsula, 3rd edn. Kuala Lumpur, Malaysia: Malay Nature Society.

Freitas AVL, and Brown KSJ. 2004. Phylogeny of the Nymphalidae (Lepidoptera: Papilionoidea). Systematic Biology 53:363-383. 10.1080/10635150490445670

Hall TA. 1999. BioEdit: a user-friendly biological sequence alignment editor and analysis program for Windows 95/98/NT. Nucl Acids Symp Ser 41:95-98.

Hanafusa H. 1989. Eleven new subspecies of Indonesian butterflies (Lep.: Papilionidae, Satyridae, Nymphalidae). Futao 3:10-13.

Harvey DJ. 1991. Higher classification of the Nymphalidae, Appendix B. In: Nijhout HF, ed. The Development and Evolution of Butterfly Wing Patterns. Washington DC: Smithsonian Institution Press, 255-273.

Kawahara AY. 2009. Phylogeny of snout butterflies (Lepidoptera: Nymphalidae: Libytheinae): combining evidence from morphology of extant, fossil, and recently extinct taxa. Cladistics 25:263-278. 10.1111/j.1096-0031.2009.00251.x

Lanfear R, Calcott B, Ho SYW, and Guindon S. 2012. PartitionFinder: combined selection of partitioning schemes and substitution models for phylogenetic analyses. Molecular Biology and Evolution 29:1695-1701. 10.1093/molbev/mss020

Miller MA, Pfeiffer W, and Schwartz T. 2010. Creating the CIPRES Science Gateway for inference of large phylogenetic trees. Proceedings of the Gateway Computing Environments Workshop (GCE). New Orleans, Louisiana. 
459

460

461

462

463

464

465

466

467

468

469

470

471

472

473

474

475

476

477

478

479

480

481

482

483

484

485

486

487

488

489

490

491

492

493

494

495

496

497

498

499

500

501

502

503

504

Moore F. 1890-1907. Lepidoptera Indica. London, UK: Lovell Reeve \& Co.

Mullen SP. 2006. Wing pattern evolution and the origins of mimicry among North American admiral butterflies (Nymphalidae: Limenitis). Molecular Phylogenetics and Evolution 39:747-758. 10.1016/j.ympev.2006.01.021

Mullen SP, Savage WK, Wahlberg N, and Willmott KR. 2011. Rapid diversification and not clade age explains high diversity in neotropical Adelpha butterflies. Proceedings of the Royal Society of London B Biological Sciences 278:1777-1785. 10.1098/rspb.2010.2140

Müller W. 1886. Südamerikanische Nymphalidaeraupen: Versuch eines natürlichen Systems der Nymphaliden. Zoologische Jahrbücher 1:417-678.

Neild AFEN. 1996. The Butterflies of Venezuela. Part 1: Nymphalidae I (Limenitidinae, Apaturinae, Charaxinae). A comprehensive guide to the identification of adult Nymphalidae, Papilionidae and Pieridae. London, Uk: Meridian Publications.

Ohshima I, Tanikawa-Dodo Y, Saigusa T, Nishiyama T, Kitani M, Hasebe M, and Mohri H. 2010. Phylogeny, biogeography, and host-plant association in the subfamily Apaturinae (Insecta: Lepidoptera: Nymphalidae) inferred from eight nuclear and seven mitochondrial genes. Molecular Phylogenetics and Evolution 57:1026-1036. 10.1016/j.ympev.2010.09.018

Peña C, and Malm T. 2012. VoSeq: a Voucher and DNA Sequence Web Application. PlosOne 7:e39071. 10.1371/journal.pone.0039071

Peña C, Wahlberg N, Weingartner E, Kodandaramaiah U, Nylin S, Freitas AVL, and Brower AVZ. 2006. Higher level phylogeny of Satyrinae butterflies (Lepidoptera: Nymphalidae) based on DNA sequence data. Molecular Phylogenetics and Evolution 40:29-49. 10.1016/j.ympev.2006.02.007

Rambaut A, Suchard MA, Xie D, and Drummond AJ. 2014. Tracer v1.6. Available at http://beast.bio.ed.ac.um/Tracer.

Reuter E. 1896. Über die Palpen der Rhopaloceren. Ein Beitrag zur Erkenntniss der verwandtschaftlichen Beziehungen unter den Tagfaltern. Acta Societas Scientiarum Fennicae 22:1-577.

Ronquist F, Teslenko M, van der Mark P, Ayres DL, Darling A, Höhna S, Larget B, Liu L, Suchard MA, and Huelsenbeck JP. 2012. MrBayes 3.2: efficient Bayesian phylogenetic inference and model choice across a large model space. Systematic Biology 61:539-542. 10.1093/sysbio/sys029

Rota J, Malm T, and Wahlberg N. 2017. A simple method for data partitioning based on relative evolutionary rates. PeerJ Preprints. 10.7287/peerj.preprints.3414v1

Schatz E. 1892. In: Staudinger O, and Schatz E, eds. Exotische Schmetterlinge 2. Germany: Bayern, [v] + [ii] $+282+[282]$ pp., 250 pls.

Smart P. 1975. The Illustrated Encyclopedia of the Butterfly World. London: Salamander Books Ltd.

Stamatakis A. 2014. RAxML Version 8: A tool for phylogenetic analysis and post-analysis of large phylogenies. Bioinformatics in press. 10.1093/bioinformatics/btu033

Tsukada E. 1991. Nymphalidae (2). In: Tsukada E, ed. Butterflies of the South East Asian Islands 5. Tokyo, Japan, 1-576.

van Velzen R, Wahlberg N, Sosef MSM, and Bakker FT. 2013. Effects of changing climate and host plant association on species diversification rates in Cymothoe (Lepidoptera, Nymphalidae) tropical forest butterflies. Biological Journal of the Linnean Society 108:546-564. 10.1111/bij.12012 
505

506

507

508

509

510

511

512

513

514

515

516

517

518

519

520

521

522

523

524

525

526

527

528

529

530

531

532

533

534

535

536

537

538

539

540

541

542
Vane-Wright R, and de Jong R. 2003. The butterflies of Sulawesi: annotated checklist for a critical island fauna. Zoologische Verhandelingen (Leiden) 343:3-267.

Wahlberg N. 2007. The subfamily Limenitidinae. Available at http://www.nymphalidae.net/Nymphalidae/Limenitidinae/Limenitidinae.htm $\quad$ accessed 16 November 2017.

Wahlberg N, Brower AVZ, and Nylin S. 2005. Phylogenetic relationships and historical biogeography of tribes and genera in the subfamily Nymphalinae (Lepidoptera: Nymphalidae). Biological Journal of the Linnean Society 86:227-251. 10.1111/j.10958312.2005.00531.x

Wahlberg N, Leneveu J, Kodandaramaiah U, Peña C, Nylin S, Freitas AVL, and Brower AVZ. 2009. Nymphalid butterflies diversify following near demise at the Cretaceous/Tertiary boundary. Proceedings of the Royal Society of London B Biological Sciences 276:42954302. 10.1098/rspb.2009.1303

Wahlberg N, Peña C, Ahola M, Wheat CW, and Rota J. 2016. PCR primers for 30 novel gene regions in the nuclear genomes of Lepidoptera. Zookeys 596:129-141. 10.3897/zookeys.596.8399

Wahlberg N, Weingartner E, and Nylin S. 2003. Towards a better understanding of the higher systematics of Nymphalidae (Lepidoptera: Papilionoidea). Molecular Phylogenetics and Evolution 28:473-484. 10.1016/S1055-7903(03)00052-6

Wahlberg N, and Wheat CW. 2008. Genomic outposts serve the phylogenomic pioneers: designing novel nuclear markers for genomic DNA extractions of Lepidoptera. Systematic Biology 57:231-242. 10.1080/10635150802033006

Willmott KR. 2003. Cladistic analysis of the Neotropical butterfly genus Adelpha (Lepidoptera: Nymphalidae), with comments on the subtribal classification of Limenitidini. Systematic Entomology 28:279-322.

Wu L-W, Lin L-H, Lees DC, and Hsu Y-F. 2014. Mitogenomic sequences effectively recover relationships within brush-footed butterflies (Lepidoptera: Nymphalidae). BMC Genomics 15:468. 10.1186/1471-2164-15-468

Zhang M, Cao T-W, Jin K, Ren Z-M, Guo Y-P, Shi J, Zhong Y, and Ma E-B. 2008. Estimating divergence times among subfamilies in Nymphalidae. Chinese Science Bulletin 53:26522658. 10.1007/s11434-008-0344-Z

Zhang M, Cao T-W, Zhong Y, Guo Y-P, and Ma E-B. 2011. Phylogeny of Limenitidinae butterflies (Lepidoptera: Nymphalidae) inferred from mitochondrial Cytochrome Oxidase I gene sequences. Agricultural Sciences in China 10:566-575. 10.1016/S16712927(11)60038-2 
543 Tables

544 Table 1. Basic statistics for each gene region used in this study.

545 Table 2. BIC scores for the different partitioning strategies as calculated by PartitionFinder.

546 "PF" means PartitionFinder was allowed to find the optimal strategy with predefined partitions

547 (by gene or by codon position by gene). "TIG" refers to TIGER partitioning using RatePartitions

548 with $d$ set to the number given (see Rota et al. 2017 for details).

549

550 Figures

551 Figure 1. The Maximum Likelihood topology for Limenitidinae with associated bootstrap

552 values. Major lineages that are considered tribes in this paper are coloured. Examples of

553 butterflies (voucher specimens for this work) from top: Parthenos sylvia, Cymothoe caenis,

554 Euriphene tadema, Euphaedra herberti, Pseudacraea poggei, Lebadea martha, Neptis ida,

555 Limenitis reducta and Adelpha californica.

556

557 Supplemental information

558 Supplemental Table S1. List of taxa used in this study with GenBank accession numbers for 559 sequenced gene regions.

560 Supplemental Figure S1. The Bayesian Inference topology for Limenitidinae with associated

561 Posterior Probabilty values. Major lineages that are considered tribes in this paper are coloured

562 as in Figure 1.

563 Supplemental Figure S2. The Maximum Likelihood topology for Limenitidinae for taxa that

564 have 10 or more gene regions sequenced. Values to the right of nodes are bootstrap values for

565 that node. Major lineages that are considered tribes in this paper are coloured as in Figure 1.

566 Supplemental Data S1. The analyzed dataset in Nexus format.

567

568 


\section{Figure 1 (on next page)}

The Maximum Likelihood topology for Limenitidinae with associated bootstrap values.

Major lineages that are considered tribes in this paper are coloured. Examples of butterflies (voucher specimens for this work) from top: Parthenos sylvia, Cymothoe caenis, Euriphene tadema, Euphaedra herberti, Pseudacraea poggei, Lebadea martha, Neptis ida, Limenitis reducta and Adelpha californica. 


\section{Table $\mathbf{1}$ (on next page)}

Basic statistics for each gene region used in this study. 
Table 1. Basic statistics for each gene region used in this study.

\begin{tabular}{|c|c|c|c|c|c|c|c|c|c|c|}
\hline Data set & Data type & $\begin{array}{l}\text { Length } \\
\text { (bp) }\end{array}$ & $\begin{array}{l}\text { Dataset } \\
\text { completio } \\
\text { n (\%) }\end{array}$ & $\begin{array}{l}\text { Variable } \\
(\%)\end{array}$ & $\begin{array}{l}\text { Pars. } \\
\text { Inf.(\%) }\end{array}$ & $\begin{array}{l}\text { Invariable } \\
(\%)\end{array}$ & $\begin{array}{l}\text { Freq. } \\
\text { A }(\%)\end{array}$ & $\begin{array}{l}\text { Freq. } \\
T / U \\
(\%)\end{array}$ & $\begin{array}{l}\text { Freq. } \\
\text { C (\%) }\end{array}$ & $\begin{array}{l}\text { Freq. } \\
\text { G (\%) }\end{array}$ \\
\hline ArgKin & nuclear & 742 & 25.3 & 33.69 & 28.3 & 66.31 & 24.42 & 19.91 & 30.51 & 25.16 \\
\hline CAD & nuclear & 850 & 12.2 & 43.29 & 34.94 & 56.71 & 35.23 & 30.71 & 13.83 & 20.23 \\
\hline COI & mitochondrial & 1475 & 84.6 & 49.97 & 40.54 & 50.03 & 29.15 & 40.03 & 16.16 & 14.66 \\
\hline СусY & nuclear & 375 & 24.8 & 36 & 31.47 & 64 & 31.83 & 31.78 & 15.69 & 20.7 \\
\hline $\mathrm{DDC}$ & nuclear & 373 & 14.4 & 44.24 & 38.34 & 55.76 & 25.4 & 28.96 & 24.38 & 21.25 \\
\hline EF1a & nuclear & 1240 & 73.8 & 35.97 & 30.65 & 64.03 & 26.75 & 22.42 & 26.5 & 24.34 \\
\hline Exp1 & nuclear & 729 & 8.6 & 35.25 & 27.57 & 64.75 & 31.76 & 30.58 & 16.47 & 21.18 \\
\hline GAPDH & nuclear & 691 & 69.1 & 40.23 & 35.31 & 59.77 & 25.16 & 27.26 & 25.25 & 22.32 \\
\hline IDH & nuclear & 710 & 34.3 & 44.08 & 39.72 & 55.92 & 32.43 & 27.31 & 18.93 & 21.33 \\
\hline $\mathrm{MDH}$ & nuclear & 733 & 18.1 & 32.88 & 20.33 & 67.12 & 28.36 & 27.03 & 21.6 & 23.01 \\
\hline Nex9 & nuclear & 420 & 25 & 43.57 & 36.43 & 56.43 & 34.33 & 25.8 & 19.42 & 20.45 \\
\hline PolII & nuclear & 360 & 24.2 & 39.17 & 35.56 & 60.83 & 31.49 & 29.65 & 16.13 & 22.73 \\
\hline ProSup & nuclear & 432 & 14.1 & 39.35 & 29.4 & 60.65 & 26.84 & 30.72 & 18.46 & 23.99 \\
\hline
\end{tabular}




\begin{tabular}{lllllllllll} 
PSb & nuclear & 366 & 24.1 & 42.62 & 40.16 & 57.38 & 28.86 & 26.14 & 22.31 & 22.68 \\
RpS2 & nuclear & 411 & 23.9 & 39.42 & 34.06 & 60.58 & 24.98 & 24.59 & 21.68 & 28.75 \\
RpS5 & nuclear & 617 & 63.5 & 41.82 & 38.74 & 58.18 & 27.44 & 25.19 & 23.01 & 24.35 \\
UDPG6DH & nuclear & 405 & 16.9 & 37.78 & 35.8 & 62.22 & 30.15 & 28.79 & 19.9 & 21.17 \\
wingless & nuclear & 400 & 78.1 & 53.5 & 42.75 & 46.5 & 23.66 & 19.56 & 27.75 & 29.04 \\
\hline
\end{tabular}




\section{Table 2 (on next page)}

BIC scores for the different partitioning strategies as calculated by PartitionFinder.

"PF" means PartitionFinder was allowed to find the optimal strategy with predefined

partitions (by gene or by codon position by gene). "TIG" refers to TIGER partitioning using RatePartitions with $d$ set to the number given (see Rota et al. 2017 for details). 
Table 2. BIC scores for the different partitioning strategies as calculated by

PartitionFinder. "PF" means PartitionFinder was allowed to find the optimal strategy with predefined partitions (by gene or by codon position by gene). "TIG" refers to TIGER partitioning using RatePartitions with $d$ set to the number given (see Rota et al. 2017 for details).

\begin{tabular}{lll}
\hline Partitions & BIC & Difference to best \\
\hline Partition_18_genes & 334394.0202 & 12525.6029 \\
Partition_PF_gene & 334060.5349 & 12192.11755 \\
LimenTIG2.0_parts & 322668.1567 & 799.739362 \\
LimenTIG4.5_parts & 322615.2355 & 746.818151 \\
LimenTIG4.0_parts & 322546.4603 & 678.042952 \\
LimenTIG3.5_parts & 322518.0154 & 649.598091 \\
LimenTIG2.5_parts & 322517.0803 & 648.662997 \\
LimenTIG3.0_parts & 322498.6547 & 630.237363 \\
Partition_PF_codon & 322411.781 & 543.363707 \\
LimenTIG5.0_parts & 321868.4173 & \\
\hline
\end{tabular}

